\title{
Building Information Modelling Implementation in Progress
}

\author{
Anetta Kepczynska-Walczak ${ }^{1}$ \\ ${ }^{1}$ Lodz University of Technology, Poland \\ Ianetta@p.lodz.pl
}

The paper presents a critical evaluation of the latest achievements in Building Information Modelling (BIM) implementation in academia, based on its adoption in Architecture curriculum at Lodz University of Technology, Poland. It reflects upon a significant shift in architectural practice which is strongly influencing ongoing modernization of higher education curricula. Furthermore, it undertakes the challenge to answer one of the main eCAADe2019 questions, viz.: "What is the impact of new technologies in architectural education and practice, and, what are the emerging opportunities and main threats to our discipline?" It contributes to the discussion on the place of BIM in academia - the controversial topic that still needs to be explored and debated to receive a comprehensive feedback and wider publicity.

Keywords: Building Information Modelling, BIM, digital technologies, collaborative design process, architectural curriculum

\section{INTRODUCTION}

The age of the 4th Industrial Revolution is profoundly shaped by the pace of change in information technologies that is accelerating, changing the way people interact with the world, communicate and function. Furthermore, the impact of digital tools on everyday life is so immense that it significantly affects the methods of work, production and processes. Digital technologies are at the core of the emerging paradigm what can be also observed in architecture and built environment domain. There is no doubt they are determining their position and role in the Architecture, Engineering and Construction (AEC) industry in the age of the 4th Industrial Revolution. The possibilities are growing and differentiating in times of prosumer dominance. It is worth noting that the terms "prosumer" and "prosumption" are not new. In the 1980 book, The Third Wave, futurologist Alvin Toffler coined the term "prosumer" when he predicted that the role of producers and consumers would begin to blur and merge (Toffler 1980). Furthermore, in his early works, dated as early as 1970, Toffler focused on technology and its impact, which he termed "information overload" and "too much change in too short period of time" (Toffler 1970). Now, fifty years later, these futuristic predictions have occurred to be present in many domains, including AEC sector and, in particular, Building Information Modelling (BIM) processes being a focus of this paper. 


\section{OBJECTIVES, STRUCTURE AND METHOD- OLOGY}

The purpose of this paper is to provide a critical evaluation of the latest achievements in Building Information Modelling implementation in academia based on its adoption in Architecture curriculum at Lodz University of Technology, Poland. It reflects upon a significant shift in architectural practice which is strongly influencing ongoing modernization of higher education curricula. Furthermore, it undertakes the challenge to answer one of the main eCAADe2019 questions, viz.: "What is the impact of new technologies in architectural education and practice, and, what are the emerging opportunities and main threats to our discipline?" It contributes to the discussion on the place of BIM in academia the controversial topic that still needs to be explored and debated to receive a comprehensive feedback and wider publicity.

It starts with an overview of a wider context of BIM in AEC sector and examples of the latest projects and publications on practical adoption of BIM, with a special focus on academia. It is followed by a brief presentation of work progress on a BIM standard in Poland. Then, the technological shift in academic curriculum at Bachelor and Master levels at Lodz University of Technology and the outcomes of the latest phase of BIM implementation are described and analysed. The new syllabus is explained and evaluated based on recently conducted courses. The paper concludes with discussing successes and drawbacks and formulates lessons for the future.

The methodological approach taken in this study is a mixed methodology based on literature review, reflected by selected references presented in the following paragraphs, concluded surveys (KepczynskaWalczak 2018), interviews conducted by the author of this paper in local architectural practices, and finally, past experience in teaching BIM (KepczynskaWalczak 2016) and present involvement in introducing multi-disciplinary and multi-actors work environment in BIM in the form of a novel BIM course in academic curriculum.

\section{CONTEXT}

To understand main objectives of this study, a wider context of BIM in AEC sector, where BIM has started to play a key role in shifting the industry, must be highlighted for the reason that according to European Union statistics the construction sector in Europe has been assessed as the second to last (sic!) in information technologies advancement and digitisation [1]. Therefore, BIM is assumed as an emerging technological and procedural shift within the Architecture, Engineering and Construction (AEC) industry and its adoption has increased significantly over the last few years. To some extends, it is an effect of various policy actions undertaken by many countries to encourage BIM diffusion. This might be exemplified by the European Parliament Directive of 2014 recommending that member States of the European Union may require the use of specific electronic tools, such as of building information electronic modelling tools or similar, for public works contracts and design contests (DIRECTIVE 2014/25/EU OF THE EUROPEAN PARLIAMENT AND OF THE COUNCIL of 26 February 2014 on procurement by entities operating in the water, energy, transport and postal services sectors and repealing Directive 2004/17/EC) [2].

A considerable literature has grown up around the theme of BIM. The applications of BIM have been researched and published for more than a decade now. Nonetheless, the topic is still high on agenda since the implementation process has not been accomplished or even started in many countries yet. The definite European leaders in this regard are the UK and Denmark. "With over a decade of experience, Denmark has become one of the European leaders in terms of BIM implementation. In 2016, 78\% of Danish design companies were aware of BIM and used it to produce 3D visualisation, carry out performance analysis on BIM and perform clash detection. Over 30\% have passed on models to those responsible for the Facility Management of buildings, showing that BIM implementation also concerns operation and maintenance phases of construction (and not only the design phase)" [3]. 
However, European countries present diverse state of art in BIM adoption. According to a recent report on situation in France, published in 2018 (Hochscheid and Halin 2018), BIM struggles to be integrated in practices of firms of the AEC sector. What is more, it has often been noticed that "innovation diffusion is slower in the AEC sector than in other industries. In France, 93\% of architecture firms are micro enterprises. Thus, for most of them (most of which work with AutoCAD and SketchUp), implementing BIM means, first of all, changing their main work and production tool. So, this is a significant and deep organizational change and financial challenge". France is not unique in this regard. Referring to the following data (Wallin and von Both 2017), "in Germany, $90 \%$ of architectural and engineering companies employ less than 10 employees. The profit generated there is often insufficient to legally exploit the cost-intensive BIM software solutions of IT companies. This is one reason why the BIM method is not widespread in Germany".

On the contrary, the R\&D domain has already appointed BIM as a shifting point in the representation, exchange, sharing and management of information, leading AEC sector transformation towards Industry 4.0. Among numerous advanced applications of BIM, a few examples have been chosen, viz. a study on a mobile BIM-based AR campus space management system (Ji, Kim and Jun 2017), a development of a technology related to file synchronisation and permission management in a cloud environment for BIM-based collaboration (Kim et al. 2016) or a proposal for an ontology-based platform for BIM semantic enrichment (Cursi, Simeone and Coraglia 2017). Regarding BIM theoretical framework, it is worth mentioning interesting examples of Succar's publications on BIM maturity matrix (Succar 2009, 2016) where author, in the span of seven years, was using the same graphical representation of his primary concept [4]. Now, ten years later, and taking into account a dynamic change in digital technologies, the initial model is still valid.

Aiming at the main focus area of the paper, the state of the art in BIM implementation in Higher Education should not be omitted. An interesting insight into the topic was given by Kocaturk and Kiviniemi (2013) where authors analysed and discussed challenges of integrating BIM in architectural education. A valuable study on how to teach BIM was published by Adamu and Thorpe (2015). According to authors, "growing industry demand and the United Kingdom government's 2016 'BIM deadline' have provided a clear impetus for enhanced BIM teaching in UK HE institutions". In this context, the authors report on a three-year implementation plan developed in a large multi-disciplinary School of Civil and Building Engineering in which 26 priority modules had their existing learning outcomes upgraded to meet the BIM learning outcomes. Another case showing the shift in academia might be exemplified by the research on a hybrid model of learning BIM in architecture education, conducted by Isanovic and Çolakoglu (2018).

Considering the fact that the paper focuses also on Polish perspective of the subject area, it is necessary to reflect on the situation in Poland. Following recent report, "Poland is at an early stage of BIM adoption. The Polish government has recently introduced policies and instruments supporting BIM implementation in its construction industry. The BIM adoption rate is relatively low, with only $12 \%$ of construction companies using BIM in their daily work. They do so mainly for activities relating to visualization, 3D models, and to a lesser extent for collision detection and use of schedules or optimization. This low adoption rate is partly explained by the lack of knowledge, the absence of (systematic) BIM requirements in public procurement law, and the high cost of BIM initial implementation" [3].

Being at initial stage of BIM adoption at the national level, Poland has been already involved in the EU BIM Task Group among other twenty European Union countries [5]. What is more, there have been regional BIM clusters established actively promoting OpenBIM. Despite there has been no standard developed and accepted by Polish government yet, the work has started. There are two main strategic ac- 
tions undergoing which tasks are as follows:

- To develop BIM standard for public procurements named "BIM standard PL" - a complete standard, after testing and pilot projects phase, should be implemented by 2025;

- To work out guidelines for Higher Education Institutions in Poland on BIM implementation in AEC courses.

Actually, the latest version of the project draft on new standards for Architecture education in Poland includes BIM suggested as a compulsory course.

In the light of the above, it is observed that Lodz University of Technology is more advanced in BIM adoption than the initiatives planned centrally. We have been teaching BIM as a tool for almost twenty years now, thanks to co-operation with GRAPHISOFT. Then, considering BIM as an integral part of design studio, the major shift in Architecture curriculum took place six years ago. Details of this change of paradigm can be found in the author's paper from 2016 (Kepczynska-Walczak 2016). In spite of such experience, it is believed the topic still needs to be explored and debated, and as a result, the course programme constantly updated. The latest implementation, that will be revealed in the following paragraphs is a BIM integrated studio course on Master level.

\section{CONCEPT}

The idea to propose advanced integrated BIM course on Master level in Architecture curriculum at Lodz University of Technology is not recent. As the fundamentals of BIM have been taught in the Institute of Architecture and Urban Planning at Bachelor level for many years now, what was described explicitly in 2016 by the author, it has become timely to develop a course on advanced level of education. The main concept was not to merely offer tutorials on a specific BIM software but to join efforts of design studio, building structures, HVAC and computer techniques laboratories, to propose an integrated course involving a variety of stakeholders and forcing teamwork and collaborative processes. The concept was elab- orated and consulted with teachers involved in the course programme and adjusted to the needs formulated by industry. It got a final shape more than a year ago, enabling the launch of the new course for the first time in autumn 2018. The concept was not to deliver yet another advanced course on BIM solely but, on the contrary, to integrate BIM into a core design course. Furthermore, parallel courses on contemporary building structures and HVAC were planned to support integrated design studio as well. Thus, different specialities were included in the same learning environment.

The course is addressed to students of the first semester of Master studies in Architecture. Majority of Master cycle students have completed the Bachelor studies in Architecture at our university. Thus, their capabilities are expected to be fairly even as well as prerequisites and skills. Since the issue of BIM has been a controversial and much disputed subject within the field of architectural education, still concentrating on the preferred software mainly, it has been decided that students will learn Autodesk Revit during this course, bearing in mind that they learnt ArchiCAD at the Bachelor cycle. Therefore, it conveys another learning gain preparing students for BIMbased marketplace.

Additional to the practical part, a set of lectures were planned to allow students to comprehend the concept of BIM assumed as the multi-actors' and multi-tasks' working environment, to learn about BIM levels, Employer's Information Requirements (EIR) and both, the pre-contract and post-contract BIM Execution Plan (BEP).

It is worth noting that it is the first course on Master level in Architecture in Poland offering such complex and integrated BIM course for architects. Referring to the previous section on BIM adoption on national level in Poland, it is expected that BIM courses will become an obligatory element of curricula in all schools of Architecture in the near future. Therefore, the presented concept, that already turned into reality, can be seen as a pioneer in the context of higher education in Poland. 


\section{IMPLEMENTATION}

There were 75 students enrolled to Master in Architecture cycle of studies. Since the integrated design studio is compulsory, not elective, all students joined the studio. The participants were divided into small groups ( 3 persons per group) to collaborate during design process. They were given a number of plots in the city centre and a list of service buildings assigned to each plot. Each team was asked to choose a plot from the list and each student, individually, was to decide on the topic from the predefined sets. It was expected each student would design one building, however in collaboration with two other colleagues who were to design their buildings on the same plot. Therefore, the scenario of teamwork built a framework for the micro-groups from the beginning. Teams started their design process with multifaceted analysis of the plots. Thus, environmental issues as well as context and local masterplan guidelines were taken into account. Since the plots were situated in urban area, an access to the chosen plots as well as a layout of a site plan had to be decided collaboratively. In some cases the concept of a common underground carpark was considered what influenced further processes. In these cases structures of the three buildings on one plot were strongly interrelated and required careful control during design process. Another task that required collaboration was to model surroundings and geometry of proposed buildings to check spatial and solar conditions.

The main learning outcome of the BIM part of the course was to gain experience in working in BIM environment from the first concept of a plot arrangement and architectural form of a designed building towards the final documentation. The software chosen was different to the one taught at Bachelor level, where students had been acquainted with ArchiCAD (GRAPHISOFT), to assure the educational offer is as rich as possible. Thus, Autodesk Revit was chosen for Master level in this regard. The questionnaire provided at the beginning of the semester revealed that only $5 \%$ of students had learned Revit before, so just few of them were not beginners. Among them one student only had some experience in using Revit in practice in AEC office. However, none of them had experience in using Dynamo, another novel element in the course.

Tutorials on Revit were provided from the beginning of the integrated course but it was observed students did not pick the tool willingly to apply it in design studio. Instead, many students started working on a design task using software they were familiar with. The most preferred tools in this regard were SketchUp for modelling, AutoCAD for technical 2D drawings and ArchiCAD for both, modelling and drawing. Some students picked Rhino to model first concepts. Therefore, there was a need to use IFC (Industry Foundation Classes) format to export data to the required platform. It was the first time students experimented with exchanging such complex data between platforms. They learned the IFC was the only open international standard for building information modelling used for sharing and exchanging construction and facility management data across different software applications. Generally, taking into account various software preferences, the idea of Open BIM was promoted throughout the course intensively, however, it brought more drawbacks than expected. Therefore, the intensive observations were undertaken, and both, successes and fails were analysed.

The final assessment of the integrated design studio based on submission and oral presentation of the project, that was to be modelled preferably in Revit. Additionally, teachers of building structures and HVAC required drawings demonstrating technical solutions. As for the BIM module, it was expected micro-teams prepared common platform in Revit showing plots' arrangements and references to individual files with their final designs of the service buildings. The files were to consist of plans, sections, elevations and animation.

Such scheme of the course forced collaborative approach in design process throughout the semester. As there were many teachers with different specialities, students had to coordinate changes not 
only in their own drawings but they had to refer also to their groups' common files. Thus, the proposed scenario imitated a real work in architectural practice and simulated the work culture in BIM.

\section{EVALUATION AND CONCLUSIONS}

This project provided an important opportunity to advance the understanding of the work culture students develop during their studies, though strongly influenced by work experience in architectural offices during their internship. It demonstrated the impact of new technologies in architectural education and practice, focusing on BIM in this regard, and showing both, opportunities and threats to our discipline.

The course allowed students to explore the multi-dimensional nature of the BIM domain and introduced a knowledge tool to assist individuals, organisations and project teams to assess their BIM capability, maturity and improve their performance. Theoretical part of the course enabled to comprehend the importance and meaning of BEP in the entire BIM process. The questions: who needs what, where, why and how, started to make sense, especially when false decisions are undertaken and, in consequence, the process has to be corrected. It was observed BEP concept appeared relatively abstract to students since majority of them did not have professional experience in large companies (those are most probably BIM-based) or on complex projects yet. On the other hand, the reality of small and medium companies does not allow for gaining such know-how, what was already discussed by the author (Kepczynska-Walczak 2018).

The formative and summative evaluations of the new course led by the author of this paper allow to draw significant conclusions.

First of all, despite digital technology being present for more than twenty years in academia, the problem of a compromise between the architect's design idea and the abilities of digital tools is still present and proves that individualisation of digital tools without the skills in programming is not reachable yet. It was visible in students' design concepts where they struggled to model imagined forms with unfamiliar tools.

Another issue reported by participants is information overload and "too much change in too short period of time" what reflects futuristic predictions published by Alvin Toffler in 1970. Furthermore, the results of the interviews conducted by the author in local architectural offices earlier this year reveal similar findings. What is striking, the opinion about the necessity of BIM implementation in daily practice is not obvious. Many architects and constructors tend to present even negative attitude and sum it up as an unnecessary revolution. This indicates a need to understand the various perceptions of BIM that exist among professionals and affect students' views.

There were also problems with platforms interoperability. Despite the promises, the Open BIM, a standard that in theory allows maximum flexibility and a seamless collaboration among all partners involved in the construction process, has appeared far from what is summarised in its definition. Exporting models between different software using IFC occurred not seamless at all, and it was one of the major disappointments and drawbacks in the process. Thus, it leads to a conclusion that despite the promises of IFC, the practical interoperability between different BIM software is still far from addressed. Referring to previous publications on this topic, "the introduction of Industry Foundation Classes has just made things worse. In fact, despite the improvement in terms of interoperability, the excessive use of IFC standards is resulting in a dangerous "representation bottle-neck", that cuts off all the knowledge that is not structured or considered in them, while the quality of the information included in the model, its accessibility, its interpretation and finally its use, or rather the theme of the semantic enrichment, is still only partially unexplored" (Simeone et al. 2013).

\section{FINAL REMARKS AND FUTURE PLANS}

The new integrated design studio based on BIM has been concluded with the lessons for the future. Stu- 
dents have learned that successful BIM adoption requires a high level of collaboration among stakeholders. However, the question is if it is not too early to expect students to see the problematics holistically without prior experience in working in BIM in architectural practice. On the other hand, the experience of internship does not bring the added value in this regard if the office is not BIM-oriented. To sum up, the new course acted as fundamentals for future complex projects in BIM environment of collaborative workflows and multi-software processes in AEC practice.

These findings have significant implications for the understanding of how to implement BIM in higher education curricula. What is more, they contribute in several ways to our understanding of teaching/learning process and provide a basis for validation and improvements of the new course. There are a number of important changes which need to be made, starting with accumulation of technical tutorials at the beginning of the semester to allow students to learn software on advanced level before they start design process. Another crucial issue is controlling and balancing requirements because feedback from students revealed that not all disciplines being involved in integrated design studio adopted BIM culture. As a result, only $2 \mathrm{D}$ drawings were required for the final assessment as well as during design process.

There is no doubt the risk was undertaken in this shift in curriculum. However, assuming the risk is a requirement for innovation it might be seen as an investment. Such approach requires long-term and constantly revised vision. Therefore, a feedback mechanism put in place to capture students' experiences regarding BIM has become crucial for further development and improvements.

The next step planned is a course that will involve students of different disciplines, not only teachers, to enable a number of specialties that can work together to simulate the work culture with BIM.

\section{REFERENCES}

Adamu, Z.A. and Thorpe, T. 2015 'How should we teach
BIM? A case study from the UK', Proceedings of the 9th BIM Academic Symposium and Job Task Analysis Review, Washington DC, USA, pp. 80-87

Cursi, S, Simeone, D and Coraglia, UM 2017 'An ontologybased platform for BIM semantic enrichment', Proceedings of the 35th eCAADe Conference - Volume 2, Rome, Italy, pp. 649-656

Hochscheid, E and Halin, G 2018 'BIM Implementation in Architecture Firms - Interviews, case studies and action research used to build a method that facilitates implementation of BIM processes and tools', Proceedings of the 36th eCAADe Conference - Volume 1, Lodz, Poland, pp. 231-240

Isanovic, H and Çolakoglu, B 2018 'Developing a Methodology for Learning BIM through EducationPractice Collaboration', Proceedings of the 36th eCAADe Conference - Volume 1, Lodz, Poland, pp. 241-246

Ji, SY, Kim, MK and Jun, HJ 2017 'Campus Space Management Using a Mobile BIM-based Augmented Reality System', Proceedings of the 22nd CAADRIA Conference, Suzhou, China, pp. 105-114

Kepczynska-Walczak, A 2016'Building Information Modelling - the Quest for Simplicity Within Complexit', Proceedings of the 34th eCAADe Conference - Volume 1, Oulu, Finland, pp. 299-308

Kepczynska-Walczak, A 2018 'Building Information Modelling for 2020+ Realm - Contemporary practice and future perspectives', Proceedings of the 36th eCAADe Conference-Volume 1, Lodz, Poland, pp. 271-280

Kim, M, Seungyeul, J, Eonyong, K and Hanjong, J 2016 'BIM-based File Synchronisation and Permission Management System for Architectural Design Collaboration', Proceedings of the 21st CAADRIA Conference, Melbourne, Australia, pp. 467-476

Kocaturk, T and Kiviniemi, A 2013 'Challenges of Integrating BIM in Architectural Education', Proceedings of the 31st eCAADe Conference - Volume 2, Delft, The Netherlands, pp. 465-473

Simeone, D, Schaumann, D, Kalay, YE and Carrara, G 2013 'Adding users' dimension to BIM', 11th conference of the European Architectural Envisioning Association, Milano, Italy, pp. 483-490

Succar, B 2009, 'Building information modelling framework: A research and delivery foundation for industry stakeholders', Automation in Construction, 18 (2009), p. 357-375

Toffler, A 1970, Future Shock, Random House, New York Toffler, A 1980, The Third Wave, Bantam Books, US

Wallner, S and von Both, P 2017 'BIM Tools Overview Target group- and process-oriented examination of 
free BIM tools', Proceedings of the 35th eCAADe Conference - Volume 1, Rome, Italy, pp. 137-146

[1] http://geo-bim.org/europe/presentation/Europeanpublic-sector-aims-for-world-class-construction-sector. pdf

[2] https://eur-lex.europa.eu/legal-content/EN/TXT/?uri $=$ CELEX:32014L0025

[3] https://buildingsmart.org.pl/wp-content/uploads/2 019/05/European-Construction-Sector-Observatory.pdf [4] https://bimexcellence.org/resources/300series/301i $\mathrm{n} /$

[5] http://www.eubim.eu/ 